\title{
Kesir Dereceli PID Denetleyici Kullanarak İçten Yanmalı Motorlarda Otonom Termal Yönetim Sistemi Tasarımı
}

\author{
Alirıza KALELí $\dot{I}^{1 *}$ \\ ${ }^{1}$ Elektrik ve Elektronik Mühendisliği Bölümü, Samsun Üniversitesi, Samsun, Türkiye
}

Geliş / Received: 9.11.2019, Kabul / Accepted: 19.12.2019

\begin{abstract}
$\ddot{O} z$
$\mathrm{Bu}$ çalışmada, kesir dereceli PID (FOPID) tipi kontrolcülerin içten yanmalı motorlarda bağımsız soğutma sistemi için tasarımı gerçekleştirilmiştir. Önerilen kontrol stratejisinde kontrolcü parametrelerinin belirlenmesinde doğrusal olamayan optimizasyon tekniği kullanılmıştır. Otonom motor soğutma şeklinde isimlendirilen bu sistem, geleneksel sisteme göre optimal 1sı yönetimi bakımından üstün bir performans sağlar. Tasarımda öncelikle soğutma sisteminin matematiksel modeli elde edilmiştir. Sonrasında soğutma sistemi bileşenleri için önerilen kontrol stratejisi hem sabit ve hem de geçici motor çalışma koşulları için test edilmiştir. Sabit çalışma koşullarında kontolcü sayesinde motor çıkış sıcaklığını izeleme hatası $0,0248^{\circ} \mathrm{C}$ ve değişken koşullarda ise sıcaklık izleme hatası ise $2,108^{\circ} \mathrm{C}$ elde edilmiştir.
\end{abstract}

Anahtar Kelimeler: içten yanmalı motorlar, termal yönetim sistemi, kesir dereceli PID, parametre optimizasyonu

The Design of Autonomous Thermal Management System For An Internal Combustion Engine Using Fractional Order PID Controller

\begin{abstract}
In this study, the fractional order PID type controller is designed an independent cooling system for internal combustion engines. Nonlinear optimization technique is used to determine the controller parameters in the proposed strategy. The system is named as autonomous engine cooling system and it provides a superior performance in terms of optimal thermal management compared to conventional systems. Fistly, the mathematical model of engine thermal system is derived. Next, in order to adjust cooling system electromechanical components, the proposed control strategy is tested both steady and transient engine operating conditions. In the steady state operating conditions, engine output temperature tracking error is $0,0248^{\circ} \mathrm{C}$ and the tracking error is obtained $2.108^{\circ} \mathrm{C}$, in variable temperature conditions.
\end{abstract}

Keywords: Internal combustion engines, Thermal management system, Fractional order PID,parameter optimization

\section{Giriş}

Günümüzde araç teknolojisi birçok sensörü, kontrol sistemlerini ve elektro-mekanik bileşenleri bünyesinde barındırmaktadır. $\mathrm{Bu}$ sistemlerin birbirleriyle uyum içinde

*Sorumlu Yazar: arizakaleli@gmail.com çalışması gerekmektedir. Geliştirilen sistemlerin hem tüketiciden gelen performans taleplerini hem de emisyon kisitlama gerekliliklerini karşılamaları gerekliliği bu sistemleri daha fazla karmaşıklaştırmaktadır. Motorlarda yakıt enjeksiyonu, ateşleme avansı gibi parametrelerin belirlenmesi ise bu 
karmaşık sistemlerin başında yer almaktadır (Xu, Zhang, Di, and Shen, 2019).

Bilindiği üzere motorlarda yakıt enerjisinin üçte biri soğutma sistemiyle dişarı atılmaktadır (John 1988). Bununla birlikte optimal termal yönetim sistemi için model tabanlı kontrol stratejilerinin uygulanması umut verici bir yaklaşım olmasına rağmen henüz gerekli ilgiyi görmemiştir (Jafari et al., 2016; Tao and Wagner, 2016). Bu durumun ana nedeni, geleneksel içten yanmalı motor soğutma sistemlerinde kullanılan pompa, mum termostat ve fan gibi bileşenlerinin pasif yapıda olup çalışmaları değişken motor çalışma koşullarına göre ayarlanamamaktadır (Pang and Brace, 2004). Bu bileşenlerden mekanik pompa gücünü krank milinden aldığından motor devriyle doğrudan bir dişli ile orantilidir. $\mathrm{Bu}$ durum ise pompanın gereğinden fazla çalışarak motorun gereksiz yere soğutulmasına ve verimli çalıştığ sıcaklı bölgesine geçme süresinin uzatılmasına neden olmaktadır. Böylece emsiyon ve çıkış gücü motor karakteristiklerini olumsuz yönde etkilenmektedir. Ayrıca geleneksel soğutma sistemindeki mum yapilı termostat ise motorun çıkış sıcaklığında dalgalanmalara neden olmaktadır. Bu durum motor çıkış sıcaklığının kararlılığını bozmaktadır. Geleneksel sistemde bu bileşenler maksimum 1sıy1 atacak şekilde tasarlanmakta ve çalışmaları motor yükü ve ortam sıcaklığg için sınır çalışma koşulları göz önünde tutularak belirlenmektedir. Fakat termal yük ve çevre sıcaklığı düşük olduğunda pompanın hızı azaltılmalı ve termostat valfinin açıklık oranı değiştirilebilmelidir. Devamlı maksimum koşullara göre çalışan soğutma sistemi bileşenleri gereksiz yere enerji tüketmektedir. Motorun 1sınma süresi uzamakta (Will and Boretti 2011), yakıt tüketimi ve egzoz emisyonları (Choi, Kim, and Lee, 2009) artmaktadır. Bundan dolayı bu bileşenlerin çalışması orta seviye termal yük için değişken termal koşullara göre düzenlenmelidir (Allen and Lasecki, 2001). Bu amaçla, geleneksel soğutma sistemlerinde motor milinden kayış tahrikli pompa yerine $12 \mathrm{~V}$ pompa ve mum termostat yerine ise servo motorlu üç yollu valf gibi aktif elemanlar kullanılmalıdır. Böyle sistemler literatürde akıllı motor soğutma sistemleri şeklinde adlandirılmaktadır (Chiara and Canova, 2013; Wang and Wagner, 2015) (Chiara and Canova, 2013).

Aktif bileşenlerin soğutma sisteminde kullanılmasiyla bunların denetlenmesi amaciyla farklı kontrol stratejileri uygulanmıştır (Jander and Baar, 2017). Bunlar arasından model öngörü kontrol (Castiglione, Pizzonia, and Bova, 2016; Hakariya, Toda, and Sakai, 2017) ise tahmine dayalı tasarımlardır. Etkili bir motor termal yönetiminde birinci amaç, motor çıkış sıcaklığının istenen değeri izlemesidir. $\mathrm{Bu}$ amaçla, Page, Hnatczuk ve Kozierowski, birden fazla elektrikli radyatör fanı ve 1S1 kontrollü termostatın olduğu soğutma sistemi için klasik PID denetleyici uygulamıştır. Test sonuçları, geleneksel sisteme göre yă̆ sıcaklığının geleneksel sistemin yarı zamanında $80^{\circ} \mathrm{C}^{\prime}$ ye ulaştığını göstermiştir (Page, Hnatczuk, and Kozierowski 2005). Soğutma sisteminin mekatronik bir sistem olarak ele alan başka bir çalışmada ise sistem GT-Cool ortamında modellenmiş ve aktüatörler için PID kontrolcüsü tasarlanarak simülasyon sonuçları verilmiştir (Iskandar and Adade Filho 2012). Castiglione, Pizzonia, Piccione, and Bova (2016), motor soğutma sisteminde çekirdek kaynamanın oluşmasını tespit etmek amaciyla silindir bloğuna bir termoçift yerleştirmiştir. Motor giriş suyu sıcaklığ 1 kontrolünü ise $85^{\circ} \mathrm{C}$ bandında tutabilmek için dijital bir PID regülatörü 
tasarlamışlardır (Pizzonia, Castiglione, and Bova 2016). Bu kontrolcünün yanı sıra soğutucu akışkanın debisini ayarlamak için Brace et al. (2001), motor çıkış sıcaklığının çıkış olarak ele alındığı bir feedforward+PID kontrolcü döngüsü geliştirmişlerdir (Pang, Brace, and Akehurst 2004).

Kontrol alanında yeni gelişmeler olmasına rağmen, PID kontrolcüsü endüstrisinde en yaygın kullanılan kontrol algoritmasıdır (Bequette, 2019; Dumlu ve Ayten, 2018; Postalcığlu ve Köktürk, 2019). Karmaşık kontrol algoritmalarına oranla basit ve uygulanabilir olması ile belirlenmesi gereken parametre sayısının azlığı bu denetleyicilerin gerçek zamanlı sistemlerde tercih edilmesinin nedenlerindendir. Fakat klasik PID parametrelerinin belirlenmesinde bazı zayıf noktalar bulunmaktadır.

$\mathrm{Bu}$ amaçla Podlubny, PID kontrolcülerin performanslarını ve kararlılığını artırmak için kesirli dereceli yaklaşımı önermişlerdir. $\mathrm{Bu}$ yaklaşım, kesirli dereceli şeklinde isimlendirilir ve $P I^{\lambda} D^{\mu}$ ile gösterilir. $\lambda$ integralin, $\mu$ ise türevin derecesini ifade eder $(\mu, \lambda>0)$ (Podlubny 1999). Son y1llarda, kesir dereceli PID $\left(P I^{\lambda} D^{\mu}\right)$ denetleyicilerin kullanımı hem teoride hem de uygulamada artış göstermiştir (Shah and Agashe 2016). Bununla birlikte bu denetleyicide fazladan iki adet tasarım parametresi de bulunmaktadır. $\mathrm{Bu}$ parametrelerin denetlenen sisteme göre optimal şekilde ayarlanmasıyla geleneksel bir PID denetleyici kullanarak elde edilemeyecek performans sonuçlarına ulaşılabilir ve en önemlisi kararlı olmayan dinamik süreçleri kontrol etme şansı kazanılabilir (Boudjehem and Boudjehem, 2013)

Bununla birlikte, parametre belirleme yöntemleri klasik de olduğu gibi FOPID denetleyici gürbüzlüğünün iyileştirilmesi için gereklidir. FOPID denetleyicinin sistem performansını önemli ölçüde artırmasına karşılık, parametre sayısındaki artış geleneksel PID kontrolöre göre katsayıların belirlenmesini zorlaştırmaktadır. Bunun için önerilen yöntemlerden parçacık sürü optimizasyonu (Zamani et al. 2009), farkl1 yapıda sezgisel yaklaşımlar (Özdemir et al. 2015; Sheng and Bao 2013) tasarlanmıştır.

Parametre belirlenmesinde optimizasyon yöntemleri uygulamada siklıkla kullanılmaktadır. Bunlardan çok değişkenli kısıtlamalı doğrusal olmayan optimizasyon yöntemleri etkili yöntemlerden biridir. Matlab ortamında kullanılan fmincon fonksiyonu gradient hesaplama prensibine, quadratik veya kübik yön arama quasi-newton yöntemine dayanmaktadır. (Büche et al. 2002; Fleming and Purshouse 2002).

$\mathrm{Bu}$ çalışmada, öncelikle Wagner tarafından geliştirilen motor soğutma sistemi oluşturulmuştur (Eberth et al. 2004; Tao and Wagner 2016). Sonrasinda bu model ifadeleri kullanılarak otonom bir motor soğutma sistemi tasarlanmıştır. Bu sistemde bulunan eyleyicilerin kontrolü için FOPID denetleyicisi tasarlanmış ve denetleyici parametrelerinin optimizasyonu için doğrusal olmayan optimizasyon yöntemi kullanılmıştır.

\section{Materyal ve Metot}

$\mathrm{Bu}$ bölümde elektro-mekanik motor termal yönetim sisteminin matematiksel modellenmesi ve kesir dereceli PID tasarımı ele alınmıştır. Model tabanlı termal yönetim sistemine ait blok diyagramı Hata! Başvuru kaynağı bulunamadı..' de verilmiştir.

\section{Motor ve Radyatörün Termal Dinamik Modeli}


Hata! Başvuru kaynağı bulunamadı.'de gösterilen sistemde soğutucu akışkan 12-Volt elektrikli pompa ile sistem içinde dolaştırılır. Motor çıkışından alınan sıcaklık ölçümlerine göre 3 yollu valf, soğutucunun bypass veya radyatör hattından dolaştırır. Geleneksel soğutma sistemindeki termostat, motor çıkışındaki akışkan sıcaklığı $90^{\circ} \mathrm{C}^{\prime}$ ye edilebilir.

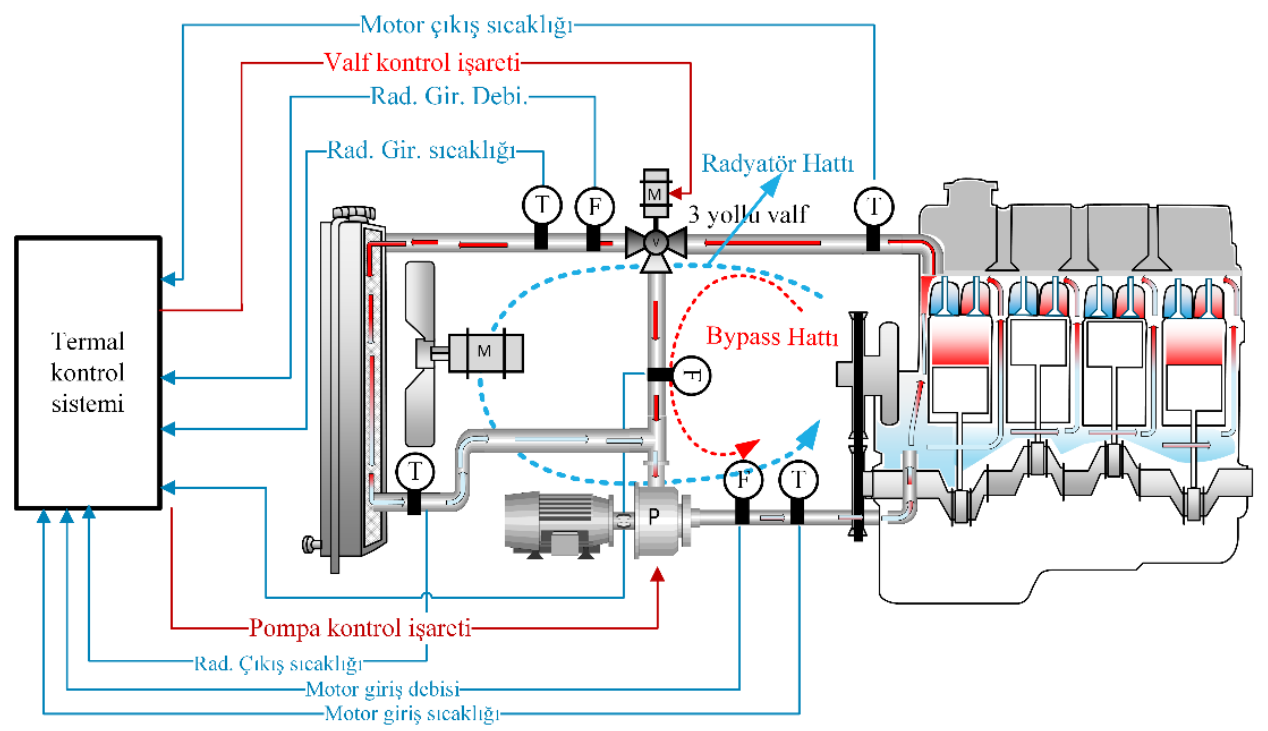

Şekil 1. Otonom motor soğutma sistemi

$C_{M o t o r} \dot{T}_{\text {motor çılkş̧ }}=Q_{\text {giriş }}-c_{\text {p,akışkan }} \dot{m}_{\text {rad. }}\left(T_{\text {motor çıkış }}-T_{\text {rad çılkış }}\right)$

$C_{\text {rad. }} \dot{T}_{\text {rad çıkış }}=-Q_{\text {çıkış }}+c_{\text {p,akışkan }} \dot{m}_{\text {rad. }}\left(T_{\text {motor çıkış }}-T_{\text {rad çıkış }}\right)-$

$\eta c_{\text {p,hava }} \dot{m}_{\text {fan. }}\left(T_{\text {motor çlkıs }}-T_{\text {çevre }}\right)$

Denklem (1) ve (2)'de kullanılan değişkenler Tablo 1'de tanımlanmıştır.

Tablo 1. Soğutma sistemi parametreleri

\begin{tabular}{|l|l|}
\hline$C_{\text {Motor }}$ & $\begin{array}{l}\text { Motor termal kapasitesi } \\
\left(\mathrm{kJ} /{ }^{\circ} \mathrm{C}\right)\end{array}$ \\
\hline$C_{\text {p,akışkan }}$ & Akışkan özgül ısısı $\left(\mathrm{kJ} / \mathrm{kg} .{ }^{\circ} \mathrm{C}\right)$ \\
\hline$T_{\text {motor çıkıs }}$ & $\begin{array}{l}\text { Motor çıkışında ölçülen } \\
\left.\text { sicaklık ( }{ }^{\circ} \mathrm{C}\right)\end{array}$ \\
\hline$T_{\text {rad çıkıs }}$ & $\begin{array}{l}\text { Radyatör çıkışında ölçülen } \\
\text { sicaklık }\left({ }^{\circ} \mathrm{C}\right)\end{array}$ \\
\hline$C_{\text {rad. }}$ & $\begin{array}{l}\text { Radyatör termal kapasitesi } \\
\left(\mathrm{kJ} /{ }^{\circ} \mathrm{C}\right)\end{array}$ \\
\hline$\eta$ & Radyatör verimi \\
\hline$C_{p, \text { hava }}$ & Hava özgül 1sıs $\left(\mathrm{kJ} / \mathrm{kg} .{ }^{\circ} \mathrm{C}\right)$ \\
\hline
\end{tabular}

\begin{tabular}{|l|l|}
\hline$\dot{m}_{\text {fan. }}$ & Fan hava debi $(\mathrm{kg} / \mathrm{sn})$ \\
\hline$\dot{m}_{\text {rad. }}$ & Radyatör hava debisi $(\mathrm{kg} / \mathrm{sn})$ \\
\hline$T_{\text {çevre }}$ & Çevre sıcaklı̆̆ $\left({ }^{\circ} \mathrm{C}\right)$ \\
\hline$Q_{\text {giriş }}$ & $\begin{array}{l}\text { Silindir içi yanma sürecinde } \\
\text { üretilen 1sı enerjisi }(\mathrm{kW})\end{array}$ \\
\hline$Q_{\text {çıkıs }}$ & $\begin{array}{l}\text { Radyatör hava akışından } \\
\text { dolayı kaybolan 1S1 enerjisi } \\
(\mathrm{kW})\end{array}$ \\
\hline
\end{tabular}

Tablo 1'de verilen parametrelerden $Q_{\text {giriş }}$ ve $Q_{c ̧ \iota k ı s ̧ ~}$ doğrudan ölçülememektedir. Soğutma sisteminin çıkış bileşenleri $T_{\text {motor çıkış }}$ ve $T_{\text {rad çıkış }}$ ile ifade edilen motor ve radyatör çıkış sıcaklıklarıdır. Bunun yanı sira, 3 yollu valfte bulunan servo motor ile valf açıklığı istenen oranda 
ayarlanabilmektedir. Valf lifti $\theta$ ile gösterildiğinde radyatörde sirküle edilen akışkan ile motorda dolaşan akışkan arasında $\dot{m}_{\text {rad. }}=\theta \dot{m}_{\text {motor }}$ şeklinde doğrusal bir ilişki bulunmaktadır. $\dot{m}_{\text {motor }}$ ifadesi aynı zamanda pompanın çıkışındaki debiyi de göstermektedir. Valf lifti yüzdelik olarak 0 ile 100 arasında değişmektedir. Burada $\theta=0$ valfin tamamen kapalı olduğunu ve akışkanın sadece bypass hattından, $\theta=100$ olmas 1 ise açık olduğu ve akışkanın sadece radyatör hattında dolaştırıldığg anlamına gelmektedir.

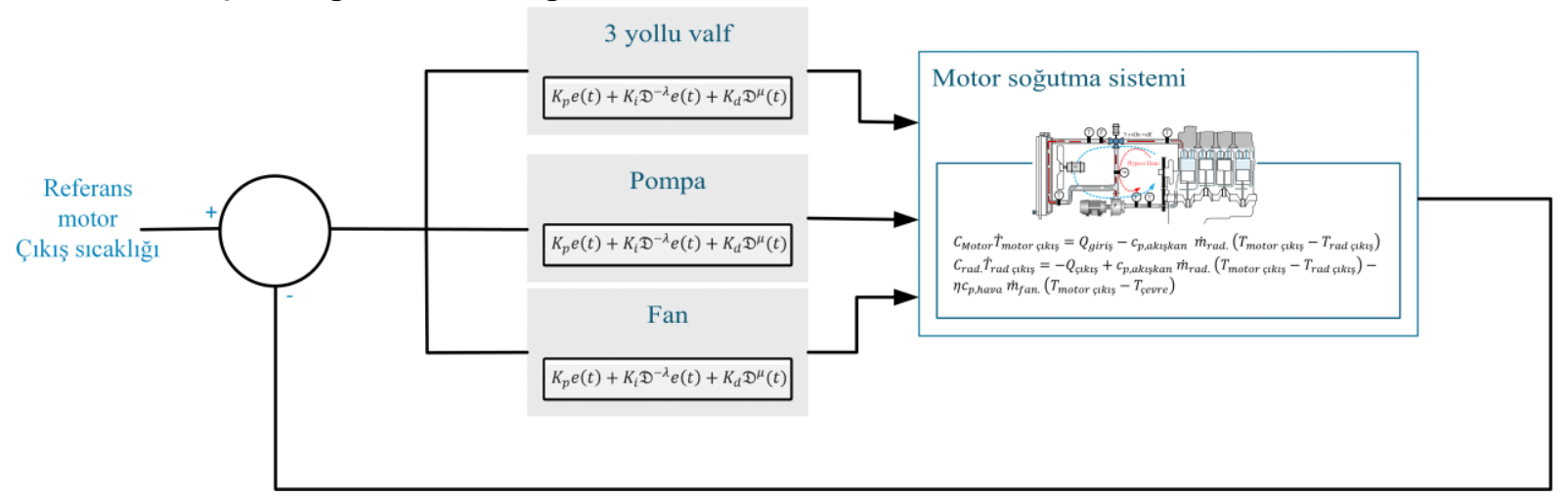

Şekil 2. Motor soğutma sistemi kontrol blok diyagramı

Kesir dereceli PID denetleyicin üretiş olduğu kontrol işareti aşağıdaki gibi ifade edilir

$u(t)=K_{p} e(t)+K_{i} \mathfrak{D}^{-\lambda} e(t)+K_{d} \mathfrak{D}^{\mu}(t)$

Burada, $e(t)$ hata işaretini, $\mathfrak{D}$, kesir derecesini göstermekte ve matematiksel olarak genellikle Grünwald-Letnikov ifadesiyle tanımlanmaktadır.

$\mathfrak{D}_{t}^{\lambda, \mu}=\lim _{x \rightarrow 0} \frac{1}{x^{\lambda, \mu}} \sum_{i=0}^{\left[\frac{t-a}{x}\right]}(-1)^{i}\left(\begin{array}{c}\lambda, \mu \\ i\end{array}\right) f(t-i x)$

Denklem (4) Laplace dönüşümünün yapılmasiyla bu ifade "s" domeninde ifade edilir.

$\mathcal{L}\left\{\mathfrak{D}_{t}^{\lambda, \mu}\right\}=s^{\lambda, \mu} X(s)$

Eşitlik (3) ile tanımlanan kontrolcü işareti ifadesinde $K_{p}$ oransal, $K_{i}$ integral ve $K_{d}$ ise türev kazanç sabitleridir. Denklem (3)'e
Dolayisiyla $\theta, \dot{m}_{\text {motor }}$ ve $\dot{m}_{f a n}$. kontrol edilen değişkenler olup önerilen denetleyici yapisiyla bu parametrelerin kontrolü gerçekleştirilmiştir.

\section{Kesir dereceli PID kontrolcü}

FOPID kontrol blok şeması Şekil 2' de gösterilmiştir.

Laplace dönüşümü uygulandiğginda ise kontrolcüye ait $s$ domeninde ifade edilir.

$G(s)=K_{p}(s)+K_{i} s^{-\lambda}+K_{d} s^{\mu}$

Eşitlik (3) ile verilen ifadede $\lambda=1$ ve $\mu=1$ olduğu zaman klasik PID kontrolcü elde edilir. Kesirli derece parametrelerin aldı $\breve{g}_{1}$ değerlere göre elde edilen kontrolcü yapısı grafiksel olarak Şekil 2'deki gösterilebilir.

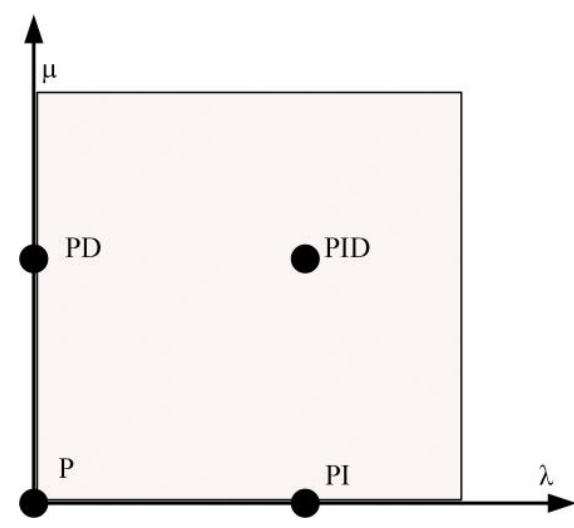

Şekil 3. $P I^{\lambda} D^{\mu}$ kontrolcü yapısı 
$\mathrm{Bu}$ grafikte görüldüğü gibi FOPID yapısı gerekli olduğu durumda klasik PID yapısına dönüştürülebilmektedir.

FOPID kontrolcüsünde parametrelerin ayarlanırken sistemin frekans cevabından yararlanılır. Sistemden istenen kazanç geçiş frekansı ve faz marjin ve değerlerine göre kazanç değerleri analitik olarak hesaplanır. Sistemin açık döngü Bode faz diyagramları elde edildiğinde kazanç geçiş frekansının olduğu noktada faz eğrisinin değişimin düz olması kapalı döngü sistemin kazanç değişimlerine karşı daha dayanımlı bir yapıya sahip olmaktadır. Literatürde FOPID kontrolörü tasarlamak için önerilen yöntemlerin çoğu bu temel fikirden faydalanmaktadır (Li and Chen 2008; Tepljakov et al. 2013)

$\mathrm{Bu}$ yöntem kullanılarak parametrelerin elde edilmesi özellikle doğrusal sistemlerde iyi sonuç vermektedir. Fakat aynı zamanda sistemin doğru bir matematiksel modelinin elde edilmesini gerektirmektedir. Sistemin açık döngü Bode diyagramının edilmesi gerçek zamanlı sistemlerde çoğu zaman zordur. Çünkü gerçek zamanlı sistemlerde doğrusal olmayan durumlar söz konusudur.

İçten yanmalı motorlarda yanma stokastik yapıdadır. Bundan dolayı bu tür sistemlerde makine öğrenmesine dayalı sezgisel yaklaşımların kullanılması daha avantajlı sonuçlar elde edilmesini sağlamaktadır.

$\mathrm{Bu}$ amaçla çalışma kapsamında doğrusal olmayan optimizasyon yöntemiyle kontrolcünün hem kazanç hem de kesirli üs türev ve integral ifadeleri otonom soğutma sisteminde motor çıkış sıcaklığını referans değerden sapmasını azaltacak şekilde belirlenmiştir.

\section{Doğrusal olmayan optimizasyon yöntemiyle parametre belirlenmesi}

Kontrolcü parametrelerinin optimizasyon yöntemiyle belirlenmesi bir maliyet fonksiyonun minimize edilmesi problemi şeklinde ele alınmaktadır. FOPID kontrolcüsünün kazanç ve kesirli üs parametrelerinin seçiminde tasarım talepleri göz önünde bulundurulmuştur. Bu çalışmada motor soğutma sisteminden beklenen, referans olarak verilen sicaklık değerinin izlemesidir. Dolayısıyla motor çıkış sıcaklığı için referans profili oluşturulmuştur. Parametre belirlemek için kalıcı hal hata değeri göz önünde bulundurulmuş ve aşağıdaki gibi tanımlanan bir maliyet fonksiyonu tanımlanmıştır.

$\min _{\varepsilon} \int_{0}^{\tau}\left(T_{\text {ref.motor çıkıs }}-T_{\text {motor çıkls }}\right)^{2}=\sum_{i=1}^{N} \varepsilon_{i}^{2}$

Denklem (7)'te sistem çıkışı ile referans arasındaki hatanın minimize edilmesi amaçlanmıştır.

Bu çalışmada, Denklem (7) ile verilen ifade doğrusal olmayan bir modelin çözümünü gerektirmektedir. Burada kullanılan optimizasyon yöntemi Trust Region yöntemi olup hata fonksiyonunun birinci ve ikinci derecede türevleri için bir bölge tanımlanmasina ve parametrelerin tahmin edilmesi prensibine dayanmaktadir. MATLAB ortamında da gerçekleştirilen parametre belirleme işleminde "fmincon" fonksiyonundan yararlanılmıştır. $\mathrm{Bu}$ fonksiyon kisitlama fonksiyonuna sahip, doğrusal olmayan ve çok değişkenli problemlerin çözümü için kullanılır. $\mathrm{Bu}$ problem için kısıt kontrolcü ifadesinde bulunan kesirli ifadeler için tanımlanmıştır. Optimizasyon probleminde parametreler ve kısıt ifade matematiksel olarak aşağıdaki gibi ifade edilmektedir. 
$\beta$

$=\left[K_{p, \text { pump }}, K_{i, \text { pump }}, K_{d, p u m p}, \lambda_{\text {pump }}, \mu_{\text {pump }}\right.$,

$\left.\ldots K_{p, \text { valf }}, K_{i, v a l f}, K_{d, v a l f}, \lambda_{\text {valf }}, \mu_{\text {valf }}\right]$

$\lambda_{\text {lim }}=\mu_{\text {lim }}=[0.01 ; 2]$

Kazanç parametrelerinde bir kısıtlama fonksiyonunu tanımlanmamasına rağmen kullanılan pompa debisi ve valfin açıklık oranı gibi sinırlamalar göz önünde bulundurulmuştur. Tüm yapılan işlemlerin sonucunda elde edilen hem valfin hem de pompanın kontrolcülerine ait parametre değerleri tablo halinde verilmiştir.

Tablo 2. Belirlenen kontrolcü parametreleri

\begin{tabular}{|l|l|}
\hline$K_{\text {p,valve }}$ & 0.4949 \\
\hline$K_{\text {p,pump }}$ & 0.5047 \\
\hline$K_{i, \text { valve }}$ & $3.4690 \mathrm{e}-04$ \\
\hline$K_{i, \text { pump }}$ & $4.3570 \mathrm{e}-04$ \\
\hline$K_{\text {d,valve }}$ & $1.1165 \mathrm{e}-04$ \\
\hline$K_{d, \text { pump }}$ & 0.0018 \\
\hline$\lambda_{\text {valve }}$ & 0.0102 \\
\hline$\lambda_{\text {pump }}$ & 0.0104 \\
\hline$\mu_{\text {valve }}$ & 0.0103 \\
\hline$\mu_{\text {pump }}$ & 0.011 \\
\hline
\end{tabular}

\section{Bulgular}

İçten yanmalı otonom motor soğutma sistemi için tasarlanan optimizasyon yöntemiyle parametreleri ayanmış bir FOPID yapısını test etmek için MATLAB/Simulink ortamında motor termal modeli oluşturulmuştur. Sonuçlar grafiksel olarak sunulmuş ve uygulanan kontrolcü yapısının motorlarda termal sistem optimizasyonunda kullanılmasının avantajlarını gösterilmiştir.
(1) ve (2) numaralı denklemlerle ifade edilen motor termal modeli üzerine parametreleri optimize edilmiş FOPID kontrol stratejisi uygulanmıştır. Model içinde kullanılan sabit değerli parametreler Tablo 3'te verilmiştir. Ayrica termal sistem farklı motor devirlerinde test edilerek model içinde yer alan $Q_{\text {girişve }} Q_{\text {çıkış }}$ ifadeleri değişken formda tanımlanarak bozucu etkilere karşı kontrolcünün performansı test edilmiştir. Bunun yanı sıra başlangıç koşulları olarak $T_{\text {motor çıkış }}(0)=20^{\circ} \mathrm{C}$ alınmıştır.

Tablo 3. Model parametreleri

\begin{tabular}{|l|l|}
\hline$C_{\text {Motor }}$ & $54\left(\mathrm{~kJ} /{ }^{\circ} \mathrm{C}\right)$ \\
\hline$C_{p, \text { akışkan }}$ & $2.36\left(\mathrm{~kJ} / \mathrm{kg} .{ }^{\circ} \mathrm{C}\right)$ \\
\hline$C_{\text {rad. }}$ & $44\left(\mathrm{~kJ} /{ }^{\circ} \mathrm{C}\right)$ \\
\hline$\eta$ & 0.1 \\
\hline$C_{p, \text { hava }}$ & $1.01\left(\mathrm{~kJ} / \mathrm{kg} .{ }^{\circ} \mathrm{C}\right)$ \\
\hline$T_{\text {çevre }}$ & $20\left({ }^{\circ} \mathrm{C}\right)$ \\
\hline
\end{tabular}

$\mathrm{Bu}$ çalışmada kontrolcünün motor çıkışında gözlemlenen sıcaklığı izleme performansı göz önünde bulundurulduğundan genlik ve frekans1 değişken referans işaretleri tanımlanmıştır. İki farklı referans giriş yapılmıştır. Birincisi sabit diğeri ise $T_{\text {ref.motor çıkıs }}=T_{0}+\sin (\alpha t)$ şeklinde ifade edilmiştir. $\alpha$ sinüs sinyalinin frekansını göstermektedir.

Buna göre öncelikle sabit motor koşullarında 1500 RPM test yapılmıştır. Ayrıca referans işareti de sabit $90^{\circ} \mathrm{C}$ şeklinde seçilmiştir. 

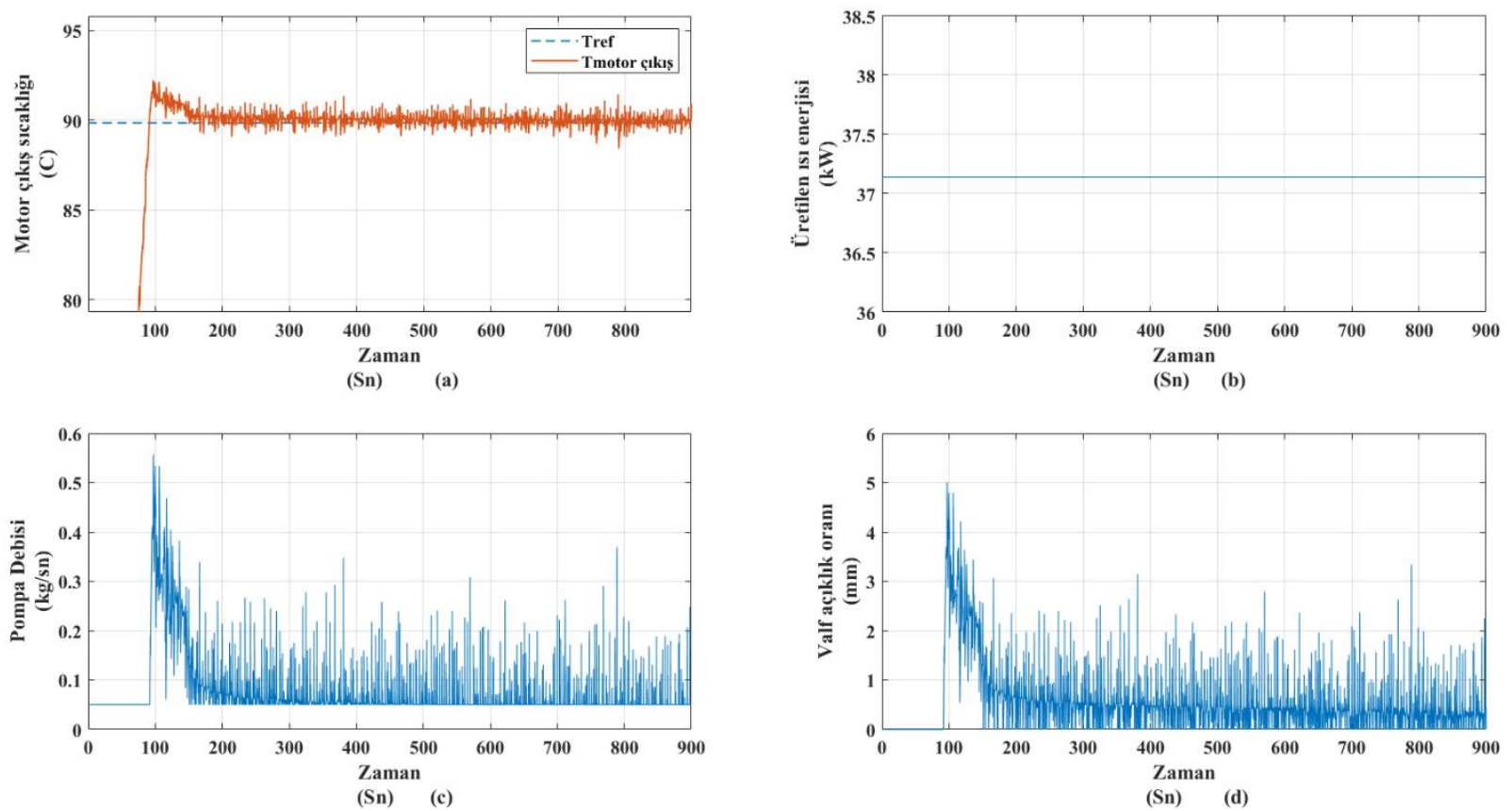

Şekil 4. Sabit termal koşullarda gerçekleştirilen birinci konfigürasyon referans ve motor çıkış sıcaklığı (a), Yanma ile oluşan ısı enerjisi (b), Pompa debisi ve valf açıklık oranı (d)
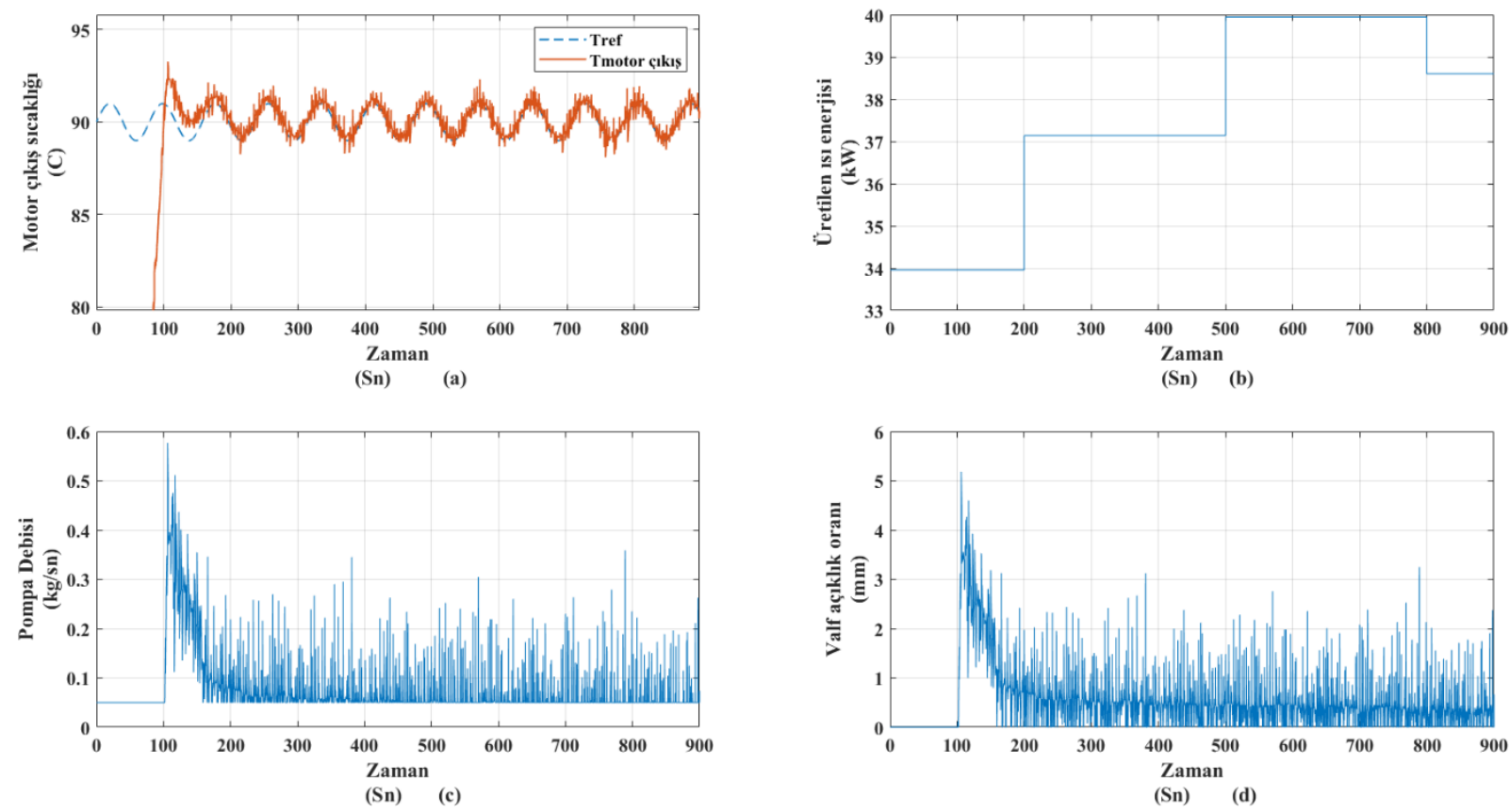

Şekil 5. Değişken termal koşullarda gerçekleştirilen birinci konfigürasyon referans ve motor çıkış sıcaklığı (a), Yanma ile oluşan ısı enerjisi (b), Pompa debisi ve valf açıklık oranı (d)

Şekil 4 ve 5 ile gösterilen sonuçlarda etrafındadır. FOPID kontrolcüsünün test tasarlanan kontrolcünün performansinı edilmesi için tanımlanan ikinci test değerlendirmek için iki senaryo uygulanmıştır. Birinci senaryoda sabit motor çalışmasının benzetimini yapılmıştır. $\mathrm{Bu}$ konfigürasyonda motorda üretilen 1s1 enerjisi sabit devir sayısından ötürü $37 \mathrm{~kW}$ senaryosunda, motor devri 1000 ile 2000 arasında değişkenlik gösterdiği için silindir içi yanma ile oluşan 1s1 enerjisi de değişken bir işaret olacaktır. Geçici hal koşullarının test edildiği bu senaryoda 200 sn. boyunca 1000 
$\mathrm{dev} / \mathrm{dk}, 200$ sn ile 500 sn. arasinda 1500 $\mathrm{dev} / \mathrm{dk}$. ve 500 ile $800 \mathrm{sn}$. arasinda ise 2000 dev/dk. 800 sn. sonra $1750 \mathrm{dev} / \mathrm{dk}$. motor devrine ayarlanmıştır. Ayrıca bu senaryoda motorun çıkışındaki referans profili oluşturulurken sabit değil değişken sinyal tanımlanmıştır. İki farklı konfigürasyon şeklinde gerçekleştirilen testlerde sabit çalışma koşullarında referans ile motor çıkış sıcaklığ 1 arasında $0,0248^{\circ} \mathrm{C}$ değişken koşullarda ise $2,108^{\circ} \mathrm{C}$ hata fark1 gözlemlenmiştir.

Tüm bu süreçler incelendiğinde klasik sistemden kaynaklanan olumsuz durumların üstesinden gelinerek sicaklık dalgalanmaları azaltılmış ve motorun özellikle referans sıcaklık değerine gelinceye kadar olan ısınma süresi klasik sistemde 200-250 sn. arasında değişirken tasarlanan sistemde ise $100 \mathrm{sn}$. seviyelerine inmiştir. $\mathrm{Bu}$ durum tamamen pompanın çalışmasıyla ilgilidir. Geleneksel sistemde pompa krank miline bağlı olup tamamen milin devrine göre çalışırken akıllı sistemde ise kontrolcünün ürettiği sinyalin genliğine göre çalışmaktadır. Böylece pompanın gereksiz yere motora su göndermesi engellenip ısınma süresi kısaltılmıştır. $\mathrm{Bu}$ şekilde çıkışta egzoz emisyonlarının ve yakıt tüketiminin azaltılması sağlanmaktadır.

\section{Sonuç}

Otomotiv endüstrisinin gelişmesine paralel olarak termal yönetim sistemlerinin de gelişmeye başlamasıyla beraber elektromekanik soğutma sistemlerinin tasarımı önem kazanmıştır. Bu çalışmada, geleneksel sistemin dışında elektrikli pompa ve 3 yollu valf kullanılarak motorda meydana gelen değişken koşullara uyum sağlayan ama aynı zamanda soğutma bileşenlerinin çalışmamaları gereken durumlarda çalışmalarını optimize eden bir kontrol sistemi tasarlanmıştır. $\mathrm{Bu}$ sistemde parametreleri doğrusal olamayan optimizasyon yöntemiyle ayarlanan kesir dereceli PID kullanılmıştır. FOPID yöntemi son yıllarda kullanımı yaygınlaşan bir yöntemdir. Dolayısıyla bu çalışma yapılan FOPID kontrol yapısının içten yanmalı motorlar gibi doğrusal olmayan birçok sürecin gerçekleştiği sistemde uygulanması büyük önem taşımaktadır.

\section{Kaynaklar}

Allen, David J, and Michael P Lasecki. 2001. "Thermal Management Evolution and Controlled Coolant Flow." https://doi.org/10.4271/2001-01-1732.

Bequette, B. Wayne. 2019. "Process Control Practice and Education: Past, Present and Future." Computers and Chemical Engineering 128: 538-56.

Boudjehem, Badreddine, and Djalil Boudjehem. 2013. "Fractional Order Controller Design for Desired Response." Proceedings of the Institution of Mechanical Engineers. Part I: Journal of Systems and Control Engineering.

Büche, Dirk, Peter Stoll, Rolf Dornberger, and Petros Koumoutsakos. 2002. "Multiobjective Evolutionary Algorithm for the Optimization of Noisy Combustion Processes." IEEE Transactions on Systems, Man and Cybernetics Part C: Applications and Reviews 32(4): 460-73.

Castiglione, Teresa, Francesco Pizzonia, and Sergio Bova. 2016. "A Novel Cooling System Control Strategy for Internal Combustion Engines." http://dx.doi.org/10.4271/2016-010226.

Chiara, Fabio, and Marcello Canova. 2013. "A Review of Energy Consumption, Management, and Recovery in Automotive Systems, with Considerations of Future 
Trends." Proceedings of the Institution of Mechanical Engineers, Part D: Journal of Automobile Engineering 227(6): 914-36. https://doi.org/10.1177/0954407012471294.

Choi, Kyung-Wook, Ki-Bum Kim, and KiHyung Lee. 2009. "Effect of New Cooling System in a Diesel Engine on Engine Performance and Emission Characteristics." SAE International Journal of Engines 2(1): 77-82. https://doi.org/10.4271/2009-01-0177.

Dumlu, Ahmet, and Kağan Koray Ayten. 2018. "Bir Otonom Elektrikli Tekerlekli Sandalyenin Hesaplamalı Tork Kontrol Yöntemiyle Yörünge Kontrolünün Gerçekleştirilmesi." Erzincan Üniversitesi Fen Bilimleri Enstitüsü Dergisi. http://dergipark.gov.tr/doi/10.18185/erzifbed. 382359 (November 4, 2019).

Eberth, John F, John R Wagner, Brian A Afshar, and Randy C Foster. 2004. "Modeling and Validation of Automotive 'Smart' Thermal Management System Architectures."

Fleming, P. J., and R. C. Purshouse. 2002. "Evolutionary Algorithms in Control Systems Engineering: A Survey." Control Engineering Practice 10(11): 1223-41.

Hakariya, Masashi, Tadashi Toda, and Mitsuto Sakai. 2017. "The New Toyota Inline 4-Cylinder 2.5L Gasoline Engine." https://doi.org/10.4271/2017-01-1021.

Iskandar, Marco Antonio, and Alberto Adade Filho. 2012. "Design and Analysis of a Cooling Control System of a Diesel Engine, to Reduce Emissions and Fuel Consumption." In ABCM Symposium Series in Mechatronics, , 39-48.

Jafari, Soheil et al. 2016. "A Review of Evaporative Cooling System Concepts for Engine Thermal Management in Motor Vehicles." Proceedings of the Institution of Mechanical Engineers, Part D: Journal of Automobile Engineering 231(8): 1126-43. https://doi.org/10.1177/0954407016674606.
Jander, Bojan S, and Roland Baar. 2017. "Modeling Thermal Engine Behavior Using Artificial Neural Network." http://doi.org/10.4271/2017-01-0534.

John, Heywood. 1988. "Internal Combustion Engine Fundamentals."

Li, HongSheng, and YangQuan Chen. 2008. "A Fractional Order Proportional and Derivative (FOPD) Controller Tuning Algorithm." In 2008 Chinese Control and Decision Conference, IEEE, 4059-63.

Özdemir, Mahmut T. et al. 2015. "Tuning of Optimal Classical and Fractional Order PID Parameters for Automatic Generation Control Based on the Bacterial Swarm Optimization." IFAC-PapersOnLine 48(30): 501-6.

Page, Robert W, Wsewolod "Jeep" Hnatczuk, and Jeffrey Kozierowski. 2005. "Thermal Management for the 21st Century - Improved Thermal Control \& Fuel Economy in an Army Medium Tactical Vehicle." https://doi.org/10.4271/2005-01-2068.

Pang, H H, and C J Brace. 2004. "Review of Engine Cooling Technologies for Modern Engines." Proceedings of the Institution of Mechanical Engineers, Part D: Journal of Automobile Engineering 218(11): 1209-15. https://doi.org/10.1243/0954407042580110.

Pang, H H, C J Brace, and S Akehurst. 2004. "Potential of a Controllable Engine Cooling System to Reduce NOx Emissions in Diesel Engines." https://doi.org/10.4271/2004-010054.

Pizzonia, Francesco, Teresa Castiglione, and Sergio Bova. 2016. "A Robust Model Predictive Control for Efficient Thermal Management of Internal Combustion Engines." Applied Energy 169: 555-66. http://www.sciencedirect.com/science/article/ pii/S0306261916301970.

Podlubny, Igor. 1999. "Fractional-Order Systems and PI $\lambda \mathrm{D} \mu$-Controllers." IEEE Transactions on Automatic Control. 
Postalcıŏglu, Seda, and Çetin Köktürk. 2019. "Bilgisayar Destekli DC Motor $\mathrm{Hiz}$ Denetimi." Erzincan Üniversitesi Fen Bilimleri Enstitüsü Dergisi. http://dergipark.org.tr/doi/10.18185/erzifbed. 510259 (November 4, 2019).

Shah, Pritesh, and Sudhir Agashe. 2016. "Review of Fractional PID Controller." Mechatronics.

Sheng, Wang, and Yan Bao. 2013. "Fruit Fly Optimization Algorithm Based Fractional Order Fuzzy-PID Controller for Electronic Throttle." Nonlinear Dynamics 73(1-2): 61119.

Tao, Xinran, and John R. Wagner. 2016. “An Engine Thermal Management System Design for Military Ground Vehicle - Simultaneous Fan, Pump and Valve Control." SAE International Journal of Passenger Cars Electronic and Electrical Systems.

Tepljakov, Aleksei, Eduard Petlenkov, Juri Belikov, and Jevgeni Finajev. 2013. "Fractional-Order Controller Design and Digital Implementation Using FOMCON Toolbox for MATLAB." In 2013 IEEE Conference on Computer Aided Control System Design (CACSD), IEEE, 340-45.

Wang, Tianwei, and John R Wagner. 2015. “A Smart Engine Cooling System - Experimental Study of Integrated Actuator Transient Behavior." http://dx.doi.org/10.4271/201501-1604.

Will, Frank, and Alberto Boretti. 2011. "A New Method to Warm Up Lubricating Oil to Improve the Fuel Efficiency During Cold Start." SAE International Journal of Engines 4(1): 175-87. https://doi.org/10.4271/201101-0318.

Xu, Zidan, Yahui Zhang, Huanyu Di, and Tielong Shen. 2019. "Combustion Variation Control Strategy with Thermal Efficiency Optimization for Lean Combustion in SparkIgnition Engines." Applied Energy.
Zamani, Majid, Masoud Karimi-Ghartemani, Nasser Sadati, and Mostafa Parniani. 2009. "Design of a Fractional Order PID Controller for an AVR Using Particle Swarm Optimization." Control Engineering Practice 17(12): 1380-87. 